\title{
SURVEY INDICATES CIRCULATION OF 4/91 AND QX-TYPE INFECTIOUS BRONCHITIS VIRUSES IN HUNGARY IN 2014 - SHORT COMMUNICATION
}

\author{
István KIss ${ }^{1}$, Tamás MATÓ ${ }^{1}$, Zalán G. HOMONNAY ${ }^{1}$, Judit KOJER ${ }^{1}$, Attila FARSANG ${ }^{2}$, \\ Ádám BÁLINT ${ }^{3}$ and Vilmos PALYA ${ }^{1 *}$ \\ ${ }^{1}$ Scientific Support and Investigation Directorate, Ceva-Phylaxia Ltd., \\ Szállás u. 5, H-1107 Budapest, Hungary; ${ }^{2}$ Directorate of Veterinary Medicinal Products, \\ National Food Chain Safety Office, Budapest, Hungary; ${ }^{3}$ Veterinary Diagnostic \\ Directorate, National Food Chain Safety Office, Budapest, Hungary
}

(Received 23 January 2015; accepted 22 June 2015)

\begin{abstract}
Understanding the epidemiology and improving vaccinal protection against the highly variable chicken infectious bronchitis virus (IBV) requires the knowledge of circulating IBV serotypes/genotypes in defined geographic areas. Accordingly, the authors initiated a survey among the major poultry producers in Hungary in order to reveal the prevailing IBV serotypes in the country. Tracheal swabs and organ samples (caecal tonsils, kidneys, and trachea) were collected from broiler, layer, and meat-type breeder flocks, and were subjected to IBV detection by virus isolation and polymerase chain reaction (PCR). The IBV-positive samples were further characterised by nucleotide sequencing and phylogenetic analysis of a portion of the S1 IBV gene. Seventeen out of the 26 submitted samples proved to be positive for IBV. Sequence analyses revealed ten $4 / 91$ and six QX serotypes, and a single D274 type IB virus. One sample contained a mixture of QX and Massachusetts serotype viruses. Presumably most of the 4/91 and D274 type viruses were vaccine strains. The proportion of QX type viruses and their observed variation are in good agreement with the situation in a few other European countries. The detected viruses clustered largely according to their geographic origin, with a few exceptions. If updated regularly, the preliminary 'virus map' will be useful for the adjustment of vaccination protocols.
\end{abstract}

Key words: Infectious bronchitis virus, diversity, Hungary

Chicken infectious bronchitis (IB), recognised in the 1930s, causes various problems in the poultry industry worldwide. Disease manifestations include respiratory and reproductive disorders, as well as kidney damages. The causative coronavirus (infectious bronchitis virus, IBV) is highly contagious, and its genome shows great variations due to mutations and recombination events. Consequently, several genotypes and serotypes exist and evolve over time. Some of

*Corresponding author; E-mail: vilmos.palya@ceva.com 
these persist and spread, while others disappear within a short time (de Wit et al., 2011). This variation undermines vaccinal protection against IB due to the lack of cross-protection between the serotypes. Although homologous vaccine strains provide the best protection against challenge or natural infections, partial protection can also be reached by appropriate combination of heterologous vaccines (Cook et al., 1996). Elaboration of proper vaccination protocols basically requires the knowledge of the prevailing serotypes in a given region/flock, and animal trials in order to determine vaccine efficacy and the protectotype of IBVs (de Wit et al., 2010). Because of the lack of such domestic data, Ceva-Phylaxia Co. Ltd. initiated a surveillance program to reveal prevalent IBV serotypes in Hungarian chicken flocks in 2014. The study was confined to partner companies of Ceva-Phylaxia and, therefore, has its inherent limitations regarding its scale. By providing archival IBV isolates from its own collection, the National Food Chain Safety Office (NFCSO) also supported this preliminary work.

Altogether 26 broiler, layer and breeder flocks were sampled regardless of the presence or lack of respiratory signs at the time of sampling, though IB associated signs were observed at each farm from time to time. Five birds per flock were sampled by means of collecting either tracheal swabs or organ specimens (caecal tonsil, kidney and trachea) from freshly collected carcasses and processing them pooled. The origin of the samples and related basic data are shown in Table 1. Six QX-type IBV samples were also provided by the NFCSO as purified RNA. These had been collected in the previous years, from the following locations: Kiskunmajsa (broiler, two farms), Szentpéterúr (broiler), Imrehegy (broiler), Szigetszentmiklós (layer), Bana (broiler).

The presence of IBV was tested by virus isolation attempts in specific pathogen free (SPF) embryonated chicken eggs, looking for the typical lesions of IBV infection, i.e. stunting and curling of the embryos, and simultaneously by PCR (Capua et al., 1999).

PCR products were submitted to nucleotide sequencing. The subsequent phylogenetic analysis was based on the 763-1129 nucleotide positions of the S1 gene (excluding the primers used for sequencing), using the Neighbour-Joining algorithm and the Kimura 2-parameter method, conducted in MEGA5 (Tamura et al., 2011).

None of the farms reported clinical signs or noticeable losses of production at the time of sampling. Eighteen submissions proved to be positive by PCR for IBV out of the sampled 26 ones, but one yielded a weak product, which was not suitable for sequencing (the positive results are shown in Table 1). The sequence analysis revealed ten 4/91, six QX-like, and one D274 type IBV. Out of the PCR positive samples, virus isolation was successful for IBV in 13 cases. 


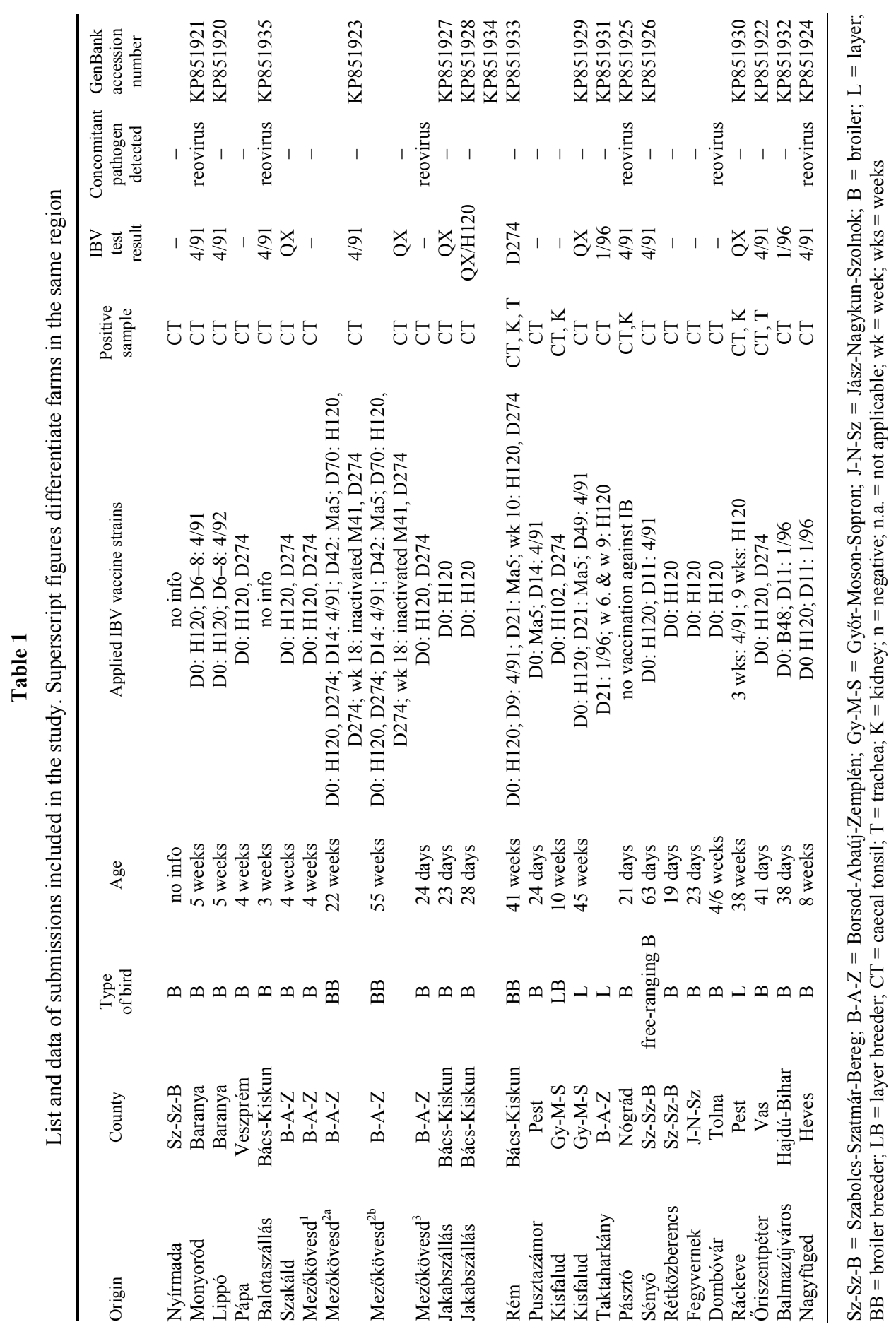


The group of 4/91 serotype IBVs seemed rather homogeneous. The amplified fragment did not allow the discrimination between vaccine and field strains. In a broiler and in a layer flock a 1/96 strain of vaccine origin was detected several weeks after vaccination. In spite of the widespread use of vaccines containing Massachusetts-type strains (de Wit et al., 2011), this serotype was not detected except in one sample containing a mixture of H120 vaccine strain and a QX-like virus in one case (28 days old broilers vaccinated with $\mathrm{H} 120$ at day-old age).

QX IBV had been first described in China in 2004 in connection with different forms of renal lesions of chickens (Liu and Kong, 2004). The QX-type IBVs have spread all over Europe and become a predominant strain (Terregino et al., 2008; de Wit et al., 2011), although so-called European QX strains are quite rarely associated with kidney problems (Worthington et al., 2008). In Hungary it was first reported in 2008 (Benyeda et al., 2009).

The present survey demonstrated the presence of QX serotype viruses in broiler, breeder and layer flocks after various vaccination protocols, even after using all registered serotypes in a broiler breeder flock (see Table 1, line Mezökövesd $^{2 b}$ ). The database was supplemented with the sequence data of the NFCSO, including strains from the past few years (Fig. 1).

The QX-like viruses formed geography-based groups, i.e. Jakabszállás and Kiskunmajsa. At the same time, high nucleotide identity in the amplified fragment was found between geographically moderately (Hajdúnánás-Mezőnyárád, approx. $60 \mathrm{~km}$ ), and considerably (Bana-Medgyesbodzás - from 2012, approx. $280 \mathrm{~km}$; Jakabszállás-Ráckeve-Szentpéterúr, approx. $200 \mathrm{~km}$ ) distant strains of QX-like viruses, suggesting epizootiological link(s) between these farms (Fig. 2).

Noticeably, the QX-like strain of Imrehegy origin, collected in 2011 by the NFCSO, separated from the rest of the QX-like group and showed high identity with A2-type strains from Xindadi and Xinnong provinces (Ji et al., 2011), regarded as nephropathogenic variants of IBV. Therefore, this strain deserves further analysis.

During the isolation process, embryo pathology characteristic of reoviruses (haemorrhagic embryos with greenish foci on their liver) was observed in six cases, and the presence of reoviruses was confirmed by virus isolation in cell culture and by PCR (Bruhn et al., 2005), either from IBV-negative (two cases) or 4/91-positive flocks (four cases), in the absence of characteristic reovirusassociated clinical signs.

This study provided a snapshot on the prevailing IBV strains in Hungary and also showed that caecal tonsils are rather useful samples for IBV monitoring purposes. Like the situation in several European countries, we also found that 4/91 and QX-like viruses are the most prevalent. While the latter certainly represent field viruses, the detected 4/91 and D274 strains can most probably be considered vaccine viruses, based on the vaccination history of the respective flocks and the spreading capacity of IBV (Cook and Mockett, 1995). 


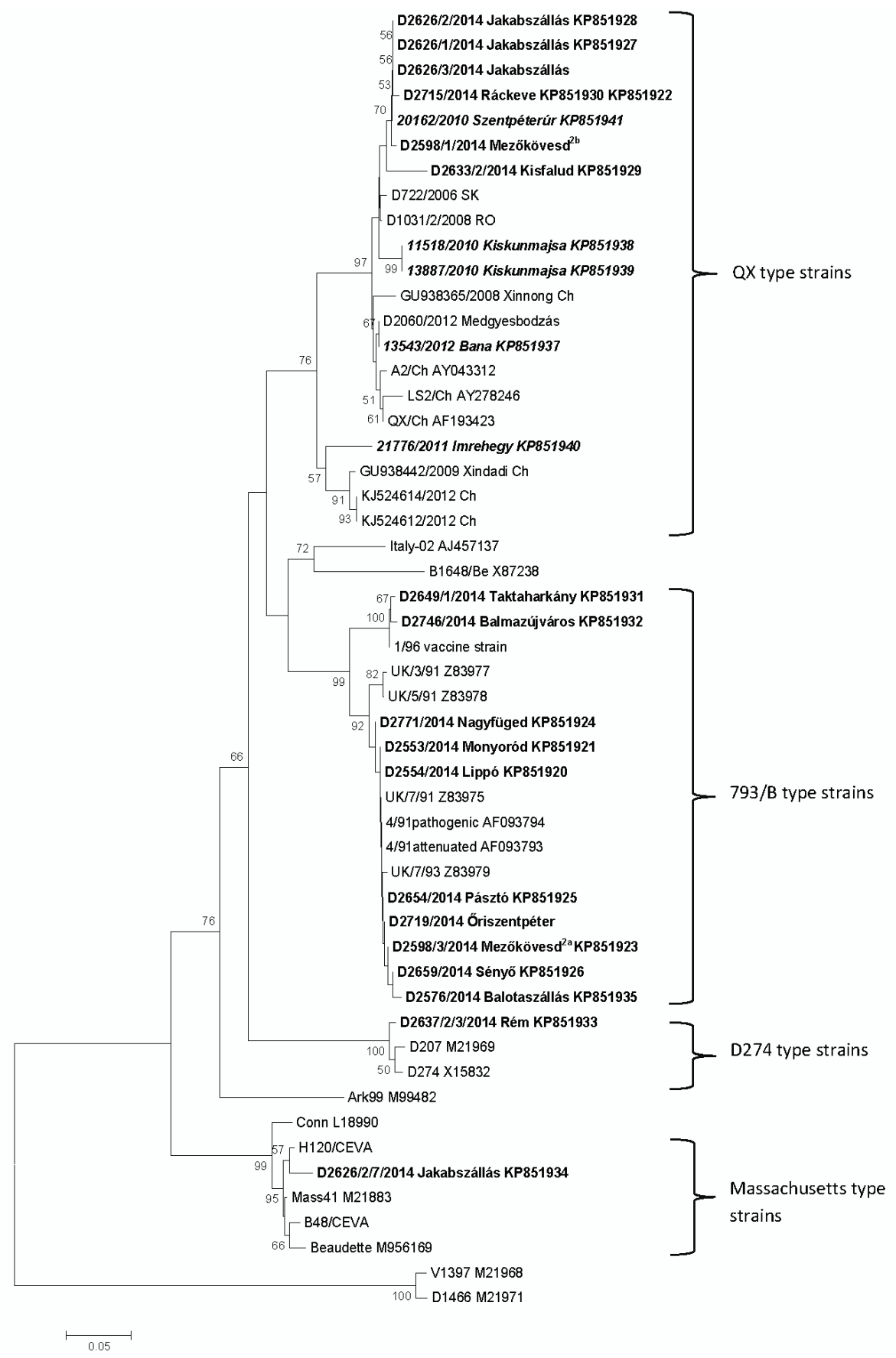

Fig. 1. Phylogenetic tree of the detected IBV strains. The bootstrap test (500 replicates) confidence levels $\geq 50 \%$ are shown next to the branches. Sequences originating from the survey are in bold letters, NFCSO samples are shown in italics 


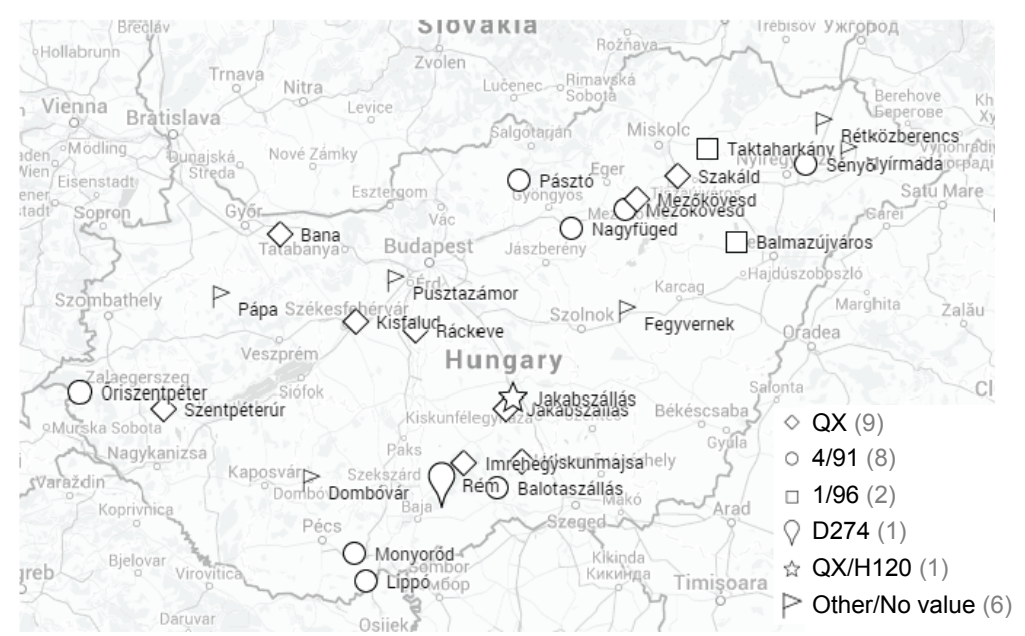

Fig. 2. Geographic distribution of the farms submitting the samples. The detected serotypes are identified with polygonal symbols

Reoviruses are frequently isolated from clinically normal chickens and the outcome of reovirus infection depends on several factors including age and immune status of the bird, route of exposure, virus pathotype, and interactions with other pathogens. Certain reovirus strains are even immunosuppressive and, thus, may enhance the severity of concomitant infections (Engström et al., 1988; Jones, 2013). While not sought for specifically, our results confirmed the ubiquitous nature of reoviruses in meat-type chickens (Jones, 2013), apparently in the lack of clinical disease.

The applied vaccination protocols appeared satisfactory for preventing the clinical manifestations of IB, but the spread of QX-like variants was obvious. This draws the attention to more targeted vaccination regimes against this serotype.

The developing 'virus map', supplemented with epizootiological information, will be useful for monitoring the efficacy of vaccination protocols. It will also show the prevalence and spread of IBV variants, thus serving the interest of farmers, vaccine companies, diagnostic laboratories and scientists involved in IBV research.

\section{Acknowledgements}

The authors acknowledge the invaluable contribution of veterinarians from the Domestic Sales Department of Ceva-Phylaxia: Mihály Albert, Zsolt Punyi, István Szigeti, István Pálfy and András Medveczki, and the technical help received from members of the Scientific Support Directorate. Attila Farsang's contribution was kindly supported by the 'János Bolyai' Research Fellowship of the Hungarian Academy of Science (BO/125/13). The authors thank Tímea Tatár-Kis for the critical reading of the manuscript. 


\section{References}

Benyeda, Z., Mató, T., Süveges, T., Szabó, E., Kardi, V., Abonyi-Tóth, Z., Rusvai, M. and Palya, V. (2009): Comparison of the pathogenicity of QX-like, M41 and 793/B infectious bronchitis strains from different pathological conditions. Avian Pathol. 38, 449-456.

Bruhn, S., Bruckner, L. and Ottiger, H. P. (2005): Application of RT-PCR for the detection of avian reovirus contamination in avian viral vaccines. J. Virol. Methods 123, 179-186.

Capua, I., Minta, Z., Karpinska, E., Mawditt, K., Britton, P., Cavanagh, D. and Gough, R. E. (1999): Co-circulation of four types of infectious bronchitis virus (793/B, 624/I, B1648 and Massachusetts). Avian Pathol. 28, 587-592.

Cook, J. K., Orbell, S. J., Woods, M. A. and Huggins, M. B. (1996): A survey of the presence of a new infectious bronchitis virus designated 4/91 (793B). Vet. Rec. 138, 178-180.

Cook, J. K. A. and Mockett, A. P. A. (1995): Coronaviridae. In: Siddel, S. G. (ed.) The Viruses. Plenum Press, New York. pp. 317-335.

de Wit, J. J., Cook, J. K. A. and van der Heijden, H. M. J. F. (2010): Infectious bronchitis virus in Asia, Africa, Australia and Latin America - History, current situation and control measures. Braz. J. Poultry Sci. 12, 97-106.

de Wit, J. J., Cook, J. K. and van der Heijden, H. M. (2011): Infectious bronchitis virus variants: a review of the history, current situation and control measures. Avian Pathol. 40, 223-235.

Engström, B. E., Fossum, O. and Luthman, M. (1988): Blue wing disease of chickens: experimental infection with a Swedish isolate of chicken anaemia agent and an avian reovirus. Avian Pathol. 17, 33-50.

Ji, J., Xie, J., Chen, F., Shu, D., Zuo, K., Xue, C., Qin, J., Li, H., Bi, Y., Ma, J. and Xie, Q. (2011): Phylogenetic distribution and predominant genotype of the avian infectious bronchitis virus in China during 2008-2009. Virol. J. 8, 184.

Jones, R. C. (2013): Reovirus infections. In: Swayne, D. E. (ed.) Diseases of Poultry. John Wiley and Sons, Inc., Ames, Iowa, USA. pp. 351-361.

Liu, S. and Kong, X. (2004): A new genotype of nephropathogenic infectious bronchitis virus circulating in vaccinated and non-vaccinated flocks in China. Avian Pathol. 33, 321-327.

Tamura, K., Peterson, D., Peterson, N., Stecher, G., Nei, M. and Kumar, S. (2011): MEGA5: molecular evolutionary genetics analysis using maximum likelihood, evolutionary distance, and maximum parsimony methods. Mol. Biol. Evol. 28, 2731-2739.

Terregino, C., Toffan, A., Beato, M. S., De Nardi, R., Vascellari, M., Meini, A., Ortali, G., Mancin, M. and Capua, I. (2008): Pathogenicity of a QX strain of infectious bronchitis virus in specific pathogen free and commercial broiler chickens, and evaluation of protection induced by a vaccination programme based on the Ma5 and 4/91 serotypes. Avian Pathol. 37, 487-493.

Worthington, K. J., Currie, R. J. and Jones, R. C. (2008): A reverse transcriptase-polymerase chain reaction survey of infectious bronchitis virus genotypes in Western Europe from 2002 to 2006. Avian Pathol. 37, 247-257. 